\title{
Heterotopic space characteristics of urban village in China: Take Guandongdian district in Beijing as an example
}

\author{
Lu Tingying, Li Jiali, Peng Ning \\ Center of Architecture Research and Design. University Of Chinese Academy Of Sciences. \\ Beijing, China \\ E-mail:1102684155@qq.com, lijiali020020@163.com,pengning18@sina.com
}

\begin{abstract}
For the first time in the history of China, more of its mainland population are living in cities than in rural villages. The land acquisition and real estate development have caused rapid disappearance and decline of a large number of traditional villages, resulting in 'urban villages' in China. They seem chaotic, but contain rich and colorful social life. The living environment is really harsh, but people always maintain close relationship with each other. They are different from neither the modern urban nor traditional villages, but they have their own unique vitality. Such heterogeneous space is always a symbol of historical change and cultural collision which, according to the French philosopher Michel Foucault, can be called Heterotopias. In order to study this heterotopic phenomenon, the triangular area of Guandongdian district in Beijing has been chosen as the object of this case study. With the in-depth investigation of interviewers, observation, statistics and sketches, this paper is trying to interpret the characteristics of the heterotopic state of the urban village from three aspects of social form, urban morphology and architectural feature. Eventually, in order to keep the complexity and diversification of urban village, several strategies are put forward for reference to future transforming practice.
\end{abstract}

Keywords: Heterotopias, space characteristics, urban village,

Guandongdian, diversification.

\section{Introduction}

In the process of rapid urbanization in China, the expansion of urban space is far beyond the pace of social development, resulting in a common phenomenon "urban village". They seem chaotic, but contain a rich and colorful social life; despite the infrastructures are in poor condition, but the residents maintain a close relationship with their neighbors; they are totally different with modern city and traditional villages, but they have their own unique vitality. Such heterotopias space is often a concentration of history development as well as cultural collision. They are easily isolated from the mainstream urban life because of its different forms of urban space, and are a very special kind of Heterotopia existed in the modern city.

\section{Theoretical Framework}

Heterotopia Theory

Foucault argues that "heterotopia" mainly has six features, namely, commonality, difference, contradiction, heterogeneous time, preset switch and bipolar space. The heterotopia is always relative to the existence of utopia: utopia is only an imagination, while heterotopia is quite real; utopia represents a perfect world, while heterotopia means a world of chaos; utopia is absolute, but heterotopia is relative. If the utopian put forward by Thomas More shows the political and aesthetic demands of modernity in the pre-modern society, Foucault's Heterotopia concept shall call for the social reality and cultural imagination formed in the process of modern postmodernism. 
In the Heterotopia theory, space should be associated with time and be more clearly defined by the objective environment outside. In all the classification and description of architecture, we are used to paying more attention to the internal space but little to the external parts. However, it is precisely the external space who gives a positioning to the internal ones, just like we use the streets, doors and other external elements to describe the location of a cafe. The Heterotopia describes a place where it can not exist independently. It demands to be positioned by another one, the "utopian", which is opposed to it. It highlights the cultural, ideological, or cultural divide between different groups of people. And it belongs to those people who are repressed, excluded, or even damaged by the prevailing social order.

\section{Urban Village}

In the narrow sense, the urban village is also known as the 'village in the city'. It refers to the ones where farmers are still living in the village houses even after it has become a residential area in the process of urbanization and all or most of the arable land was requisitioned. Broadly speaking, the urban village can be defined as residential areas of low living standards. In the process of rapid development of the city, it lags behind the pace of the times and away from the modern management system.

From the nature of the concept of the heterotopia, we observe that the phenomenon of urban village has many heterotopic spatial features. From the perspective of time, the old elements are likely to be eliminated in the development of the city, while the new elements will be established instead. For a specific time node, the rationality of the past is now becoming unreasonable. Just because it is no longer reasonable, it is inevitably eliminated and isolated, becoming the island in the city. However, from today's view, these island left behind by the society are exactly the best view point for us to observe the history.

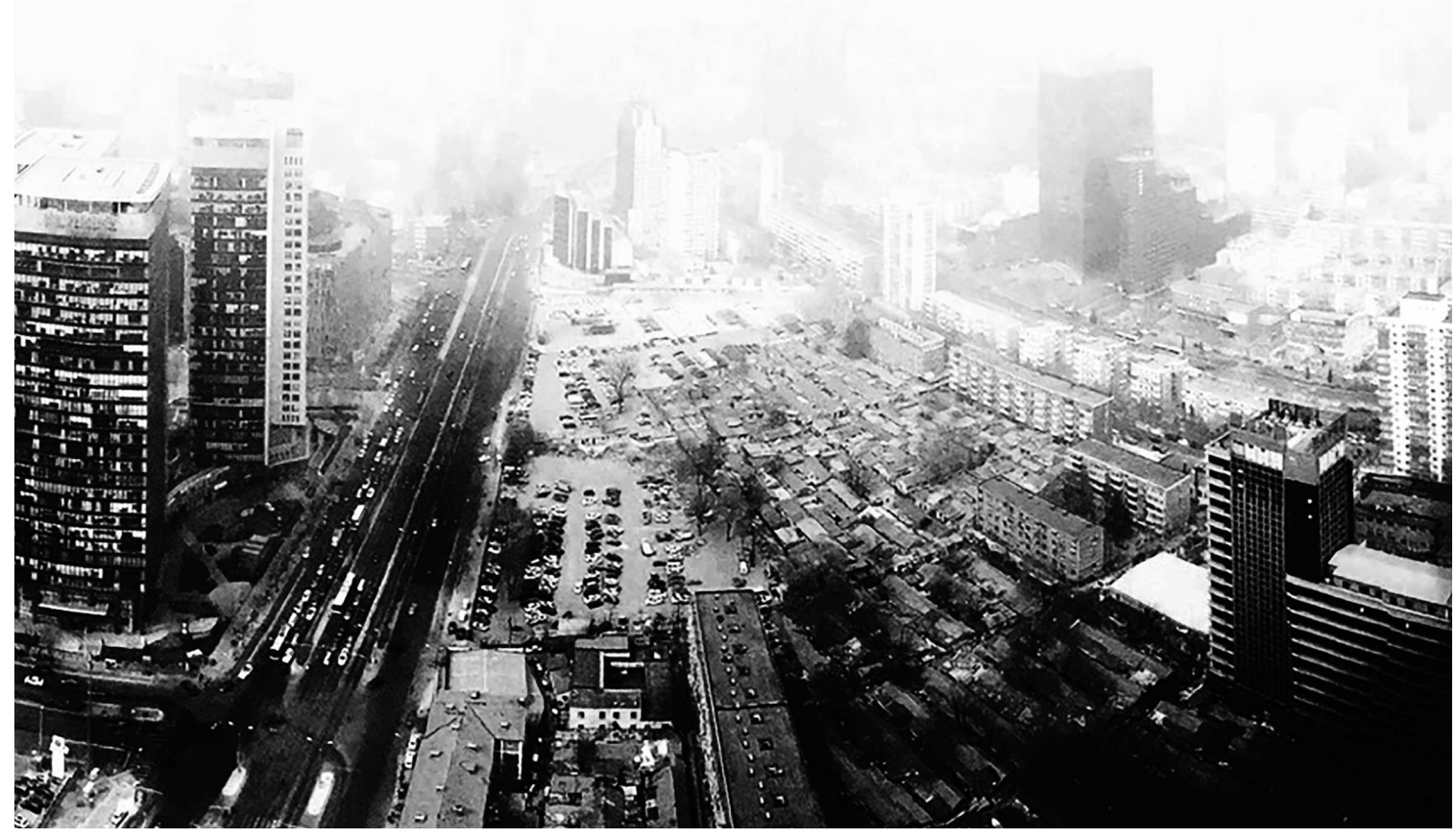

Figure 1.

Overlooking the site 


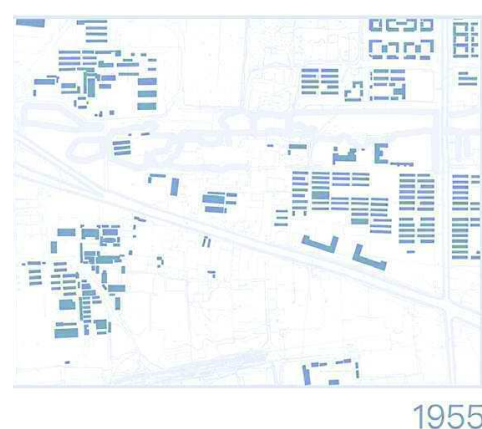

1955

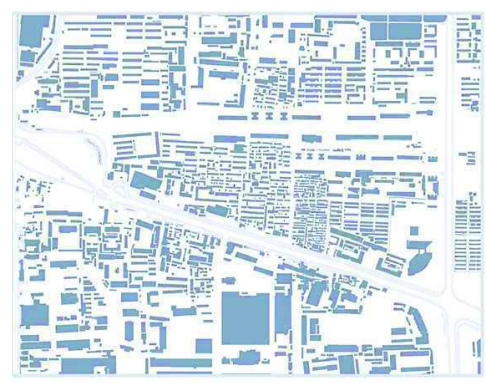

1989

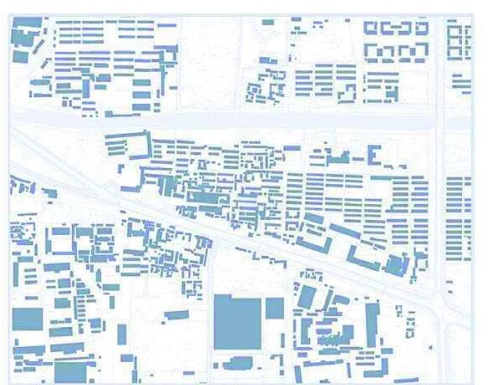

1964

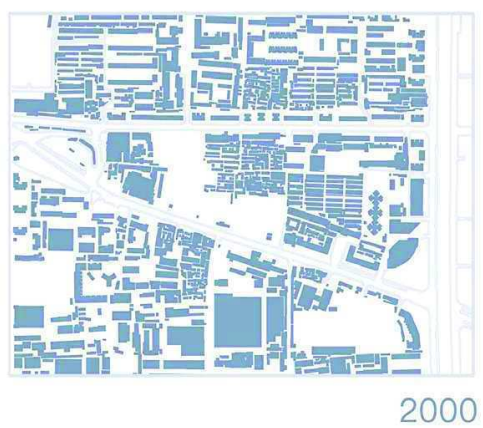

2000

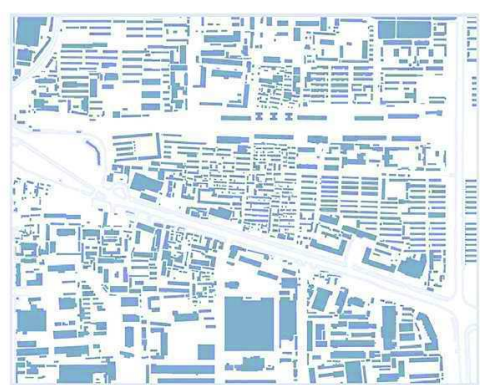

1979

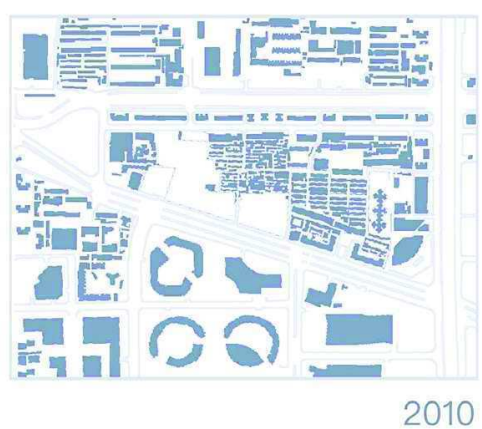

Figure 2.

Topology map of the triangle area and the surroundings from 1955 to 2010

\section{Background: Guandongdian Triangle District in Beijing}

As is known to all, Beijing has especially regular city planning, majestic central axis and countless ambitious buildings. Despite of this, when taking a closer look at its streets network, we will still find some interesting ramps. Guandongdian triangle area is one of these interesting cases, continuing to change during the long history of the urban construction and social relations.

Located in the west of Chaoyang District in Beijing, Guandongdian triangle is near the transfer station of the Metro Line 6 and Line 10. It is west to Xiangjunnanli, east to the East Bridge Road and the Dongdaqiao Workers Stadium, south to the Guandongdian North Street and south to Chaoyangmenwai Street. Chaoyangmenwai Street is a tilt street from the northwest to the southeast, leading to the triangular shape of Guandongdian area. The location of this tilt street can be very important. During the Ming and Qing Dynasties, it performed as the transport path. The foods went along the waterway from Tongzhou to Beijing, and then transported on the land to Chaoyang Gate. Even until today, this street is still leading to Tongzhou. (Figure 1,2)

Before the founding of new China, Guandongdian area is a part of Gaobeidian village, mainly formed by farmlands and farmhouses. Then after 1949, there are supposed to build new dormitories of 3501 People's Liberation Army and fishery company, so the original farmhouses ware all removed. In addition to that, the farmlands have also been destroyed for a number of bungalows. According to historical records, the east-west waterway had not been filled with roads until the time between 1964 and 1979, forming the existing Chaoyang North Road. Nearly in the same period, the triangle area was divided into two parts. The shantytowns at west side belong to Huashiying village, while the the neat singlestorey buildings at the east side are the old 3501 dormitories. As one of the few triangular areas in Beijing's lattice-like city, Guandongdian has witnessed the rise from the peasant household and the collective dormitory to the surrounding CBD high-rises from the 1950s till now.

From the economic, cultural, planning and other academic level, most scholars are regarding the urban villages of chaotic forms as a negative phenomenon to be criticized. Some scholars have summarized five negative 
impacts of all the urban planning, land revenue, municipal public facilities construction, industrial structure and social stability which are mostly led by urban villages. Starting from this, they further explore transformation strategies. But objectively speaking, the phenomenon of urban village is a typical and special example of urban development. Its typicality lies in its wide distribution, while its particularity lies in their social progress brought about by special historical phenomenon which is directly related to the rapid urbanization as well as the influx of the rural population into the city. Therefore, the study of such cases and analysis of their spatial characteristics could have possibly help us to deeply understand the nature of space, and finally provide references to the further transformation strategies.

\section{Heterotopic characteristics}

\section{Social morphology}

From the perspective of social composition, Guandongdian area is detached from the development of modern society to a great extent. It is far behind the pace of social progress, and even contradicted with the new urban construction strategy. From this point, there is no doubt that the urban village of Guandongdian is unenlightened and limited. The surrounding cities have been developing so fast that a clear isolation zone appears between the urban village and the mainstream cities. Also, there exists difficulties of dismantling of local blocks and obvious separation on both sides within the urban village community.

With a large number of migrants pouring in, the residents in a certain part of Guandongdian become quite different from the ones in another part. In Huashiying area, there are mostly temporary tenants nowadays, which are of great mobility. In order to seek survival, these foreign populations have developed a complete industrial chain, perfectly meeting the requirements of low - income populations. According to the statistics, this chain consists of 11 clothing shops, 17 restaurants, 33 markets and 14 other necessity shops. Within such a small urban village, its industrial structure is rather complete and various, completely forming a micro closed society. In contrast, the 3501 dormitory on the east are mostly residents of generations. They have been living here for at least three generations. Compared with Huashiying area, its social composition is relatively simple. Many of the tenants here are the original aborigines, so the neighborhoods are very familiar with each other.

Nevertheless, it is such a chaotic scene that breeds the the fruit-vegetable shops and those tiny breakfast shops at the streets. These cityoriented formats give birth to a vibrant public communication space. At around 8:30 every morning, when the people working in the surrounding CBD walk out from the Hujialou subway station, many of them deliberately get into Guandongdian area in order to have a cup of milk and a pancake in the breakfast shops, and then rush into the office building. At noon, these business people will cross the venue, looking for cheap restaurants with their friends. And after work, they may come to the fruit-vegetable stores or butcher shops on their way home for lower price than the regular supermarket. Overall, Guandongdian urban village has provided affordable living supplies for the workers who are eager to save money. It is now a logistics platform for the people in the high-rises around. Correspondingly, the business people have brought a steady stream of passengers for these inferior industries. Their relationship can be described as mutually beneficial and win-win situation.

\section{Urban morphology}

The heterogeneity of the urban level is mainly reflected in the scale of open space such as the streets, street corners and the edged space.

At the beginning of their construction, different communities have been mutually exclusive. They have no interaction with the original textures, so the junctions can be really hard. For example, there are no rules for the distribution of houses in Huashiying areas. Lack of management and planning, there happens spontaneous additions or alterations all the time. On the contrary, the 3501 dormitory built after it strictly follows the planned layout of the determinant. Except for the original 


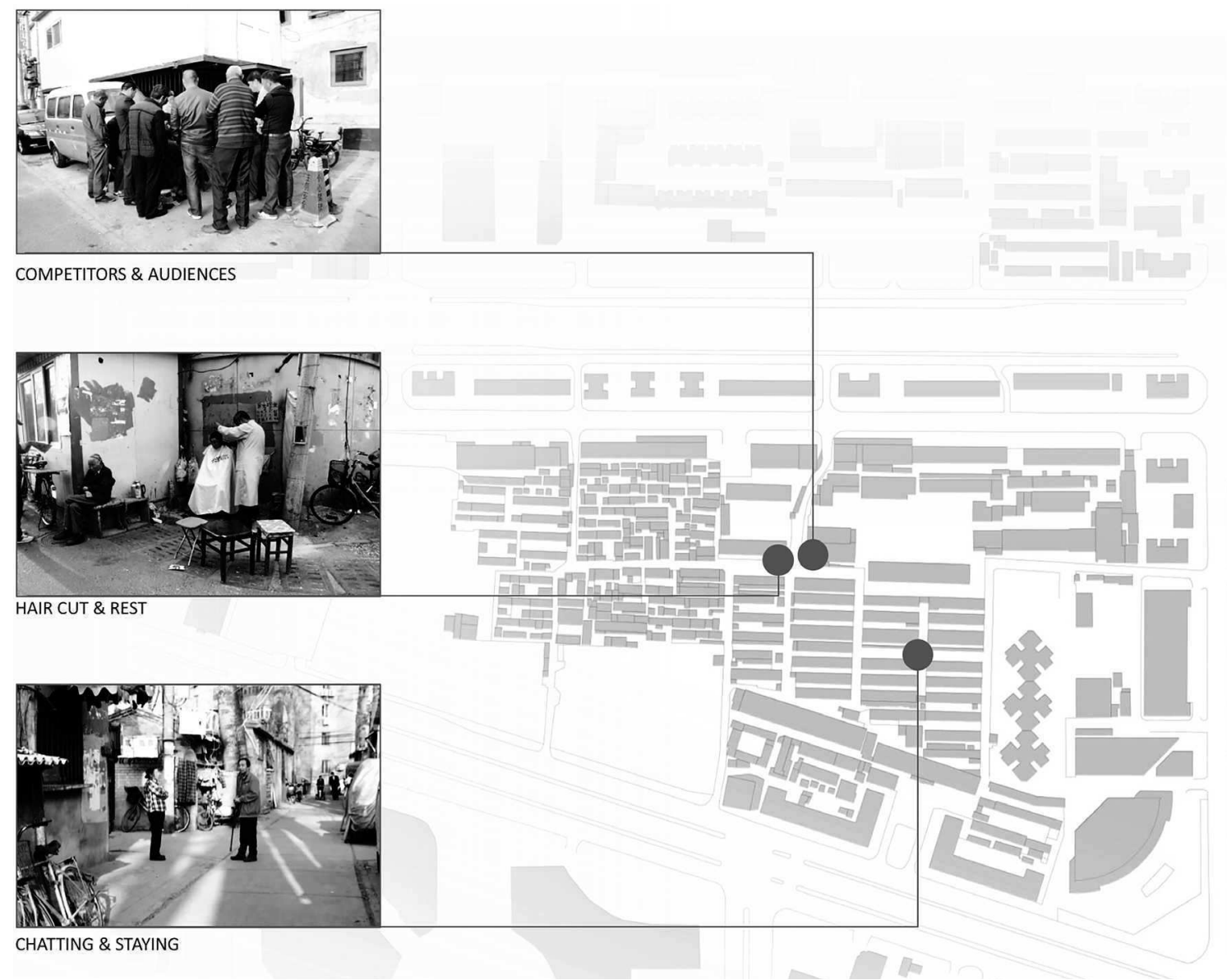

Figure 3.

\section{Activities at street corners}

chaotic between the communities and the roads, the illegal construction by the tenants are increasingly blocking the access. Although the floor area rate is quite low, but the building density is really high. Before 20th century, the city block planning in China didn't seriously consider the passages of motor vehicles. The roads within a block are people-oriented, and much of the street scales are no more than two meters' width. But as the development of the times, the electric bicycles, electric tricycles and some private cars are pouring into the blocks. During lunch and dinner hours, crowds of delivery cars pass through the field, driving so fast that bringing a great threat to pedestrians. There are also many office workers living nearby would prefer riding a bike through the venue. Apparently, such a narrow street has been unable to meet the needs of modern city traffic. In other words, the motor vehicles are destroying the suitable environment of a block for the pedestrian.
In the research process, we focus on the space form generated when the collision occurs between different textures. We found that those space corners which are seemingly irregular or difficult to use are somehow the ablest to stimulate the interaction between people's activities. In fact, it is the high density of the buildings planned at the beginning that leads to such a tense urban public space. However, humans are creatures having the instinct of social interaction. They never stopped their eager for the public communication space. Even if the conditions are limited and do not allow a comfortable space for communication, people can create conditions for organizing activities by themselves. On the one hand, the street corners have a natural advantage to stimulate the public activities of the city which provide a place for communication. For instance, their functions are hardly fixed and the space are fully opened to the public, so that the activities occurring here can be easily observed and 


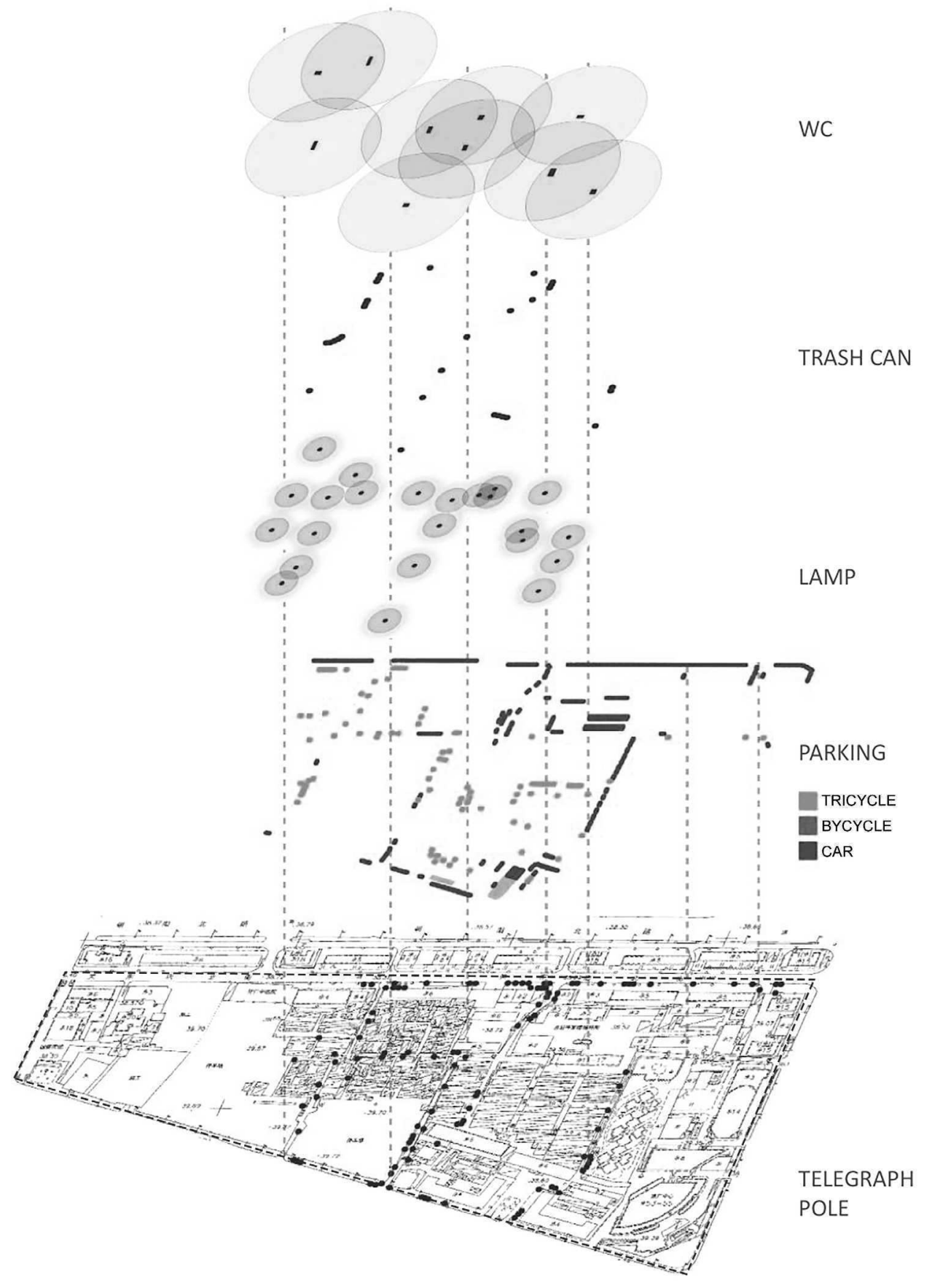

Figure 4.

Urban elements in the site

shared. Residents and their neighborhoods are free to occupy the place, never subject to their class or economic conditions. Since the corner space can be easily arrived, it often becomes a focus of a certain area. However, there is no denying that the corner space also has obvious flaws. They are in the formation of the visual center, but at the same time, usually become traffic nodes with significant risks. More over, it is hard for them to meet the needs of comfort because of the lack of leisure facilities (Figure 3).

In addition, the infrastructures in Guandongdian area are of serious damage and backward. The public toilets can not be cleaned up in time and their cleaning situation is worrying; the sanitation of street corners and public toilets next to the trash directly and 


$\left.\begin{array}{l}1950-\text { Gaobeidian farm house } \\ 1952-\text { People's Liberation Army } 3501 \text { dormitory } \\ 1960 \\ 1970 \\ 1990 \\ 1993 \\ 2008\end{array}\right] \begin{aligned} & \text { Fishery company dormitory } \\ & \text { Beijing station relocatees } \\ & \text { Municipal cleaning team resettlement housing } \\ & \text { Jingguang Center Apartment } \\ & \text { Housing authority development } \\ & \text { Continue to build }\end{aligned}$

Figure 5.

Building ages on the site
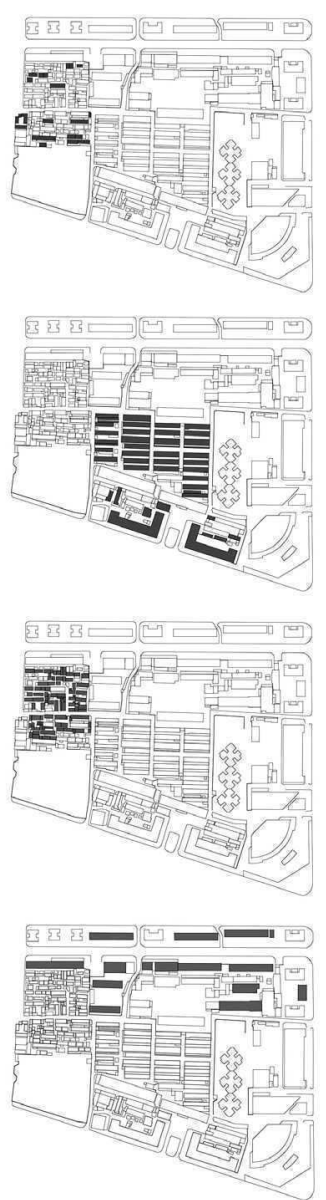
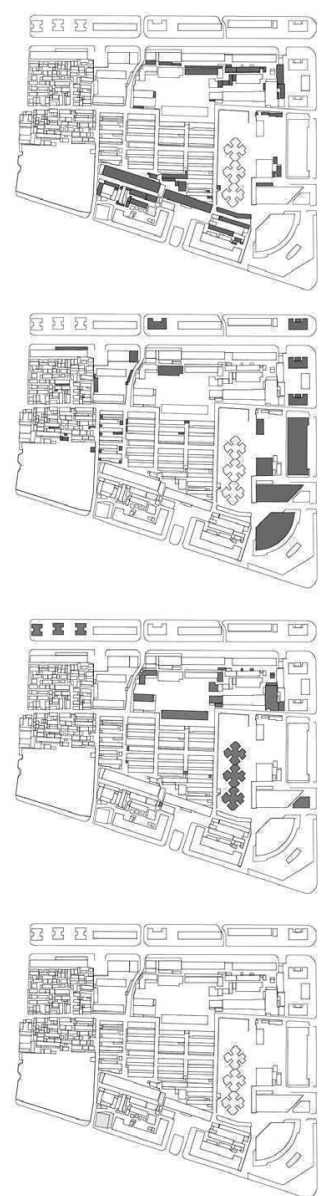

visibly impacts the daily lives of the citizens; the limited quantity of street lamps lead to frequent traffic accidents at night; a large number of motor vehicles occupy the sidewalk as parking space, for there is no centralized parking place; poles are mostly woods on the stone seats, the woods are seriously rotten; countless wires entangled in the air with the popularity of network and bring about potential dangers (Figure 4). These negative conditions are urgent to be concerned about in the future transformations.

\section{Architectural characteristics}

From the architectural level, the urban village gathers in the buildings of various ages, just like a vivid history museum (Figure 5). Whether it is gradually dilapidated 3501 dormitories, fishery company dormitories, Beijing station demolition houses, or the hotel apartment Jing Guang Center constructed in the nineties which still maintain its high quality, all of them represent a certain era from their building structure, materials, style. Even from the view of today, despite that their initial function has ceased to exist, but the basic structure of the building makes them still identifying. The residential changed into shops, the streets were occupied by food markets, and the appearance of the buildings have also undergone great changes. The buildings of the 3501 dormitory area are single-storey townhouses with brickand-white structures. Their windows are small, and the distance between each two is less than half the depth of the building which directly leads to poor ventilation (Figure 6). In the early 1990s, the Jing Guang Center at the southeast corner of the venue was completed and brought a great obstacle to the dormitory area. Jing Guang Center is of the 52-story on the ground part, reaching 209 meters' high. It is a set of five-star hotels, senior office buildings as well as luxury apartments for the integrated 
building. Such two opposite elements are only 100 meters away, the current consumption level and living quality in 3501 dormitories is much lower than the latter. The former volume rate is about 0.5 while the latter is up to 35 , which means that despite the hardware conditions of the dormitories is far behind the Jing Guang Center, but per capita possession of land area is much higher than the latter. It is predictable that if this urban village could be fortunately preserved in the future, then it is likely to become a place charming and suitable enough to walk.

The architecture layout in Guandongdian is of great diversity. A row of residential buildings along the Chaoyangxiejie is arranged parallel to the the city's main street. After the Tangshan earthquake, the structures of the buildings were carefully reinforced and the red and white appeared on the facade. On the other side, the gray-based buildings are located beside the 3501 dormitories, facing the south direction. At the interface of these different types of buildings, there is no transitional treatment. It has created the negative space between the buildings, affecting the street style. More than this, it could possibly become the breeding of crime because the corner is dark and inaccessible. Few conversations happen between the building blocks out of the difference in age and background. All the single-storey, multi-storey and high-rise buildings symbiotic here, creating a sense of drama.

\section{Transformation strategy}

The ultimate goal of interpreting the heterotopias spatial characteristics of urban village is to guide the city's village renovation more effectively. And the purpose of transforming the urban village is to make it integrated into the modern urban space. For the village itself, the transformation of space is the requirement of improving the living environment and creating a good place to live. The problem of living environment originally

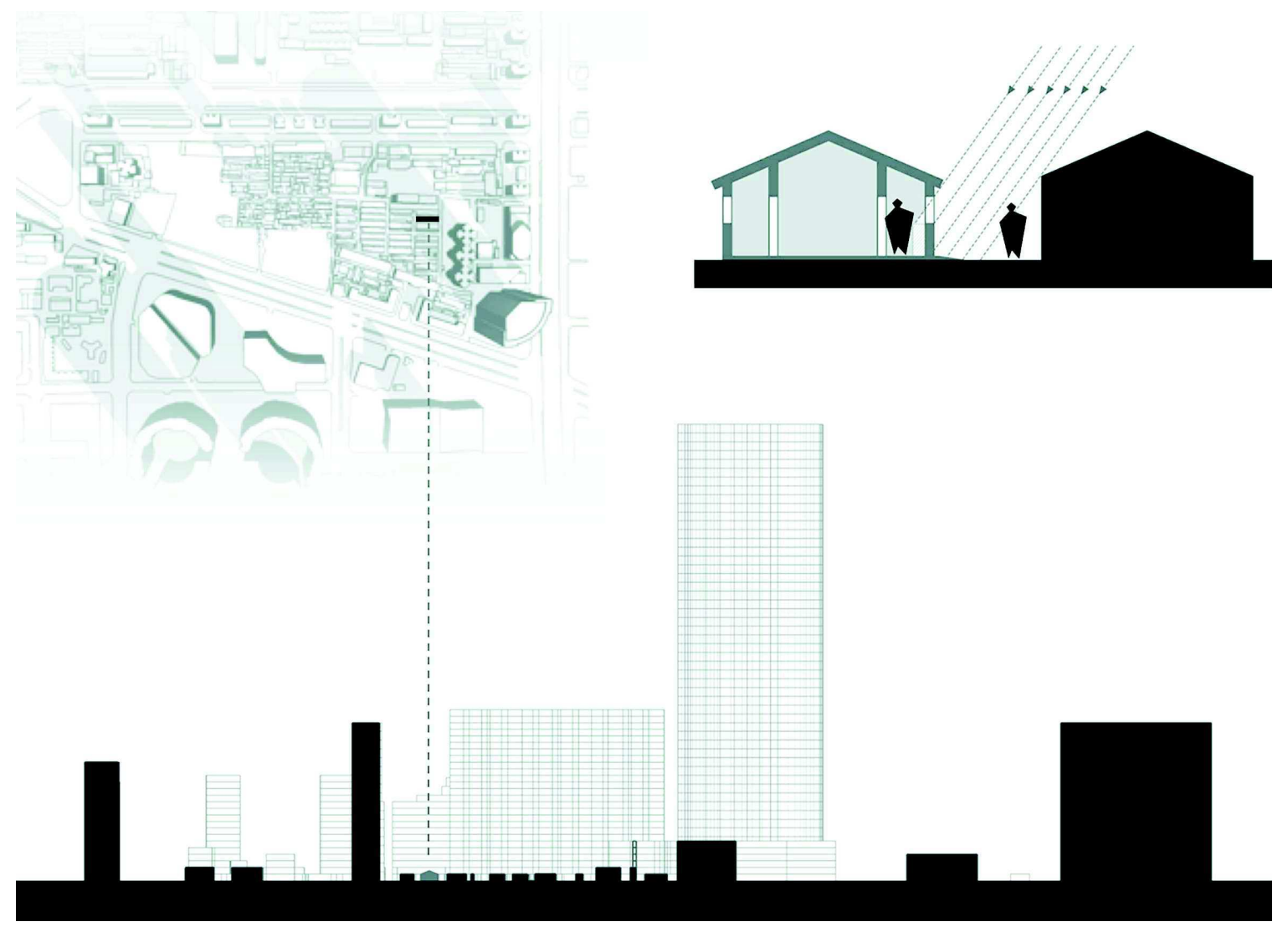

Figure 6.

Light condition of a certain house of 3501 dormitories 
comes from the space, so the final solution must also be implemented into the space.

In public space, people will be largely affected by the psychological and behavioral effects. According to their own purpose and psychological state, most people are free to choose a comfortable place to stay. Therefore, it is important to design the corresponding facilities in the public space. From the research and analysis, the street corners can be regarded as unique places in the urban village and always the spontaneous choice of the residents for gathering. Its advantages must be preserved and made full use of, while its defects on stability, safety and comfort aspects should be solved at the same time. When it comes to urban design, municipalities and architect groups need to take necessary measures to properly intervene. For example, the pavement materials and color of street corners can be high lightened to distinguish from the street area, the lighting of the corner area requires unified transformation, and the slowdown zone could be set on the street close to the corner.

For architectural individuals, their symbolic significance is much higher than the practical value. Today, the Huashiying area and the 3501 dormitories in Guandongdian are almost unprotected and repaired, and the building structures have been in serious problems for a long time. For the future city, such a lowdensity block is likely to produce incredible opportunities such as supporting the residents to start their own businesses, setting up creative workshops, appropriately introducing some high-quality services. These measures may inspire architects and community residents to cooperate in building renovation, promoting the enthusiasm of residents to participate in enhancing building quality and ensuring the daily maintenance of the buildings partially by themselves.

In general, the transformations of urban village are supposed to adhere to the existing format as the core of the city, to respect the citizens as the main body and to recognize the architects as assistants in the transformation and regeneration mechanism, and finally encourage the community coordination under the guidance of the government.

\section{Conclusion}

As time goes on, the living space of urban village is constantly varying. The nature of the heterotopia is 'different', which represents the recognition and respect of urban complexity, the critique of utopian perfection in urban planning, and the negation of indiscriminate brutal demolition. The 'difference' in the urban village is that it has triple heterogeneity at the social, urban and architectural levels. Heterotopic theory has provided an interpretation of this heterogeneous space whose variety of social structure and urban space form a common phenomenon of urban village. Although not the mainstream of the city, but it has a unique vitality and cohesion. In the process of rapid urban development, we have the obligation to protect their individuality in social culture.

The urban village is part of the modern city. It exists in the form of a village, but is located in the city textures. For this reason, if the urban village hopes to develop into a positive space, it has to make full use of its great advantages of low density, be open to the city and provide service for the city. It not only means to change its role from the small self-enclosed society into a strong logistics service area, but also to organize a safe and comfortable public communication platform for both the city and the buildings. Only in this way can the urban village maintain a unique heterogeneity, and meanwhile change the negative space into a positive one, create tremendous value for the modern city.

\section{References}

Abraham, S. (2013) 'The heterotopic space of Chirag Delhi', unpublished research paper, Guru Gobind Singh Indraprastha University, Delhi.

Foucault, M. (1967) Of Other Spaces: Utopias and Heterotopias, Trans. Miskoviec, J. (1984), (http://foucault.info/documents/ heteroTopia/foucault.heteroTopia.en.html) accessed 21 May 2017.

Ryuzo, O. and Kobayashi, M. (2015) Human metropolitan studies, Trans. Yu, Y and Yin, 
Q. (2015) (China Architecture and Building Press, Beijing).

Wang, S. (2013) 'Heterotopias versus Cultural Imagination: An Interpretation of the Metropolitan Space of Tianjin from the Perspective of Michel Foucault's Of Other Spaces (Heterotopias)' Journal of Nanyang Normal University 12, 50-53.

Wang, Y. (2002) 'The Enlightenment of Foucault and His Heterotopias to Architecture', Architectural Journal 11, 6264.

Wang, Y. and Xia, J. (2010). "On the 'Heterotopias' Traits of the Historic District." Modern Urban Research: 62-68. 